ERLA ERLENDSDÓTTIR

UNIVERSIDAD DE ISLANDIA

\title{
Vanadio, itrio, ángstrom... \\ En torno a términos científicos de origen nórdico en español
}

\section{Introducción}

$\mathrm{L}$ os estudios dedicados a la historia del léxico de la lengua española han experimentado un notable aumento en décadas recientes. Cabe señalar en este sentido los estudios del léxico medieval, las investigaciones sobre el léxico del lenguaje de especialidad y los estudios respecto a la etimología y la documentación del léxico, así como el análisis de la evolución semántica del léxico y la perspectiva histórica de la morfología derivativa. ${ }^{1}$

En el ámbito de la lexicología histórica se halla la investigación de los lenguajes de especialidad, cuyo objetivo principal es el estudio del origen y evolución de la terminología de diversas áreas de especialidad. Es aquí, precisamente, donde se sitúa el estudio del vocabulario científico y técnico. Inscritos en este campo existen diversos estudios e investigaciones en torno al léxico de la ciencia y de la técnica; este léxico específico es, además, objeto de estudio de distintos proyectos en curso. Cabe destacar el estudio del léxico de la medicina cuyos resultados aparecen en el Diccionario español de textos médicos antiguos,

1 Clavería Nadal, Gloria, "Nuevas perspectivas en el estudio de la evolución del léxico", en Clavería Nadal, Gloria, Margarita Freixas Alás, Marta Prat Sabater y Joan Torruella I Casañas (eds.), Historia del léxico: perspectivas de investigación, Madrid/Frankfurt am Main: Iberoamericana/Vervuert, 2012, pp. 13-90. 
obra dirigida por María Teresa Herrera; ${ }^{2}$ la elaboración de un diccionario de la ciencia y de la técnica en el Renacimiento (DICTER), dirigido por María José Mancho Duque; ${ }^{3}$ los estudios de Juan Gutiérrez Cuadrado y Cecilio Garriga Escribano sobre el léxico de la química, que, con la creación del grupo NEOLCYT, se ampliaron a otros diversos terrenos de especialidad con el fin de confeccionar el Diccionario bistórico del español moderno de la ciencia y de la técnica. ${ }^{4}$ Del dinamismo y de la productividad en este ámbito ofrecen testimonio además publicaciones como, por ejemplo, la Historia del léxico español, de 2007, una colección de artículos coordinada por Mar Campos Souto, Rosalía Cotelo García y José Ignacio Pérez Pascual; ${ }^{5}$ Etimología e historia en el léxico del español, de 2016, coordinada por Mariano Quirós García, José Ramón Carriazo Ruiz, Emma Falque Rey y Marta Sánchez Orense; ${ }^{6}$ y Lengua de la ciencia y lenguajes de especialidad, libro editado por Cecilio Garriga, María Luisa Pascual y María Betulia Pedraza en 2019?

Nuestra indagación, que se enmarca en el ámbito de la historia del léxico, se centra en el examen del vocabulario relacionado con el mundo de la ciencia. El propósito del presente trabajo es, en particular, analizar varios términos científicos españoles procedentes del germánico septentrional. Ello implica que el estudio también se adscribe al ámbito del préstamo léxico y se integra, de hecho, en una investigación más amplia que está en marcha sobre voces de origen nórdico incorporadas al español; al respecto vale anotar que con el término

2 Herrera, María Teresa (dir.), Diccionario español de textos médicos antiguos (DETEMA), Madrid: Arco Libros, 1996.

3 Mancho Duque, María Jesús (dir.), Diccionario de la ciencia y de la técnica en el Renacimiento, http:// dicter.usal.es/.

4 Para más información remitimos a la página web del grupo NEOLCYT: http://dfe.uab.es/neolcyt. Véase, además, el artículo de Rodríguez Ortiz, Francesc y Cecilio Garriga Escribano, "El Diccionario Histórico del Español Moderno de la Ciencia y de la Técnica (DHEMCYT): resultados y perspectivas" en Sinner, Carsten (coord.), Comunicación y transmisión del saber entre lenguas y culturas, Madrid: Peniope, 2013, pp. 401 410. https://dialnet.unirioja.es/servlet/libro?codigo=559895.

5 Campos Souto, Mar, Rosalía Cotelo García y José Ignacio Pérez Pascual (coord.), Historia del léxico español, A Coruña: Universidade da Coruña, 2007.

6 Quirós García, Mariano, José Ramón Carriazo Ruiz, Emma Falque Rey y Marta Sánchez Orense (eds.), Etimología e historia en el léxico del español, Madrid/Frankfurt am Main: IberoamericanaVervuert, 2016.

7 Garriga, Cecilio, María Luisa Pascual y María Betulia (eds.), Lengua de la ciencia y lenguajes de especialidad, Anexos de Revista de Lexicografía, 42, A Coruña: Universidade da Coruña, 2019. Se trata del resultado de la investigación del grupo La Red Temática «Lengua y Ciencia» que está conformado por 38 grupos internacionales. Para más información ver: https://www.lenguayciencia.net/ grupos/todos-los-grupos/. 
nordismos nos referimos a los vocablos que provienen directa o indirectamente de las lenguas germánicas septentrionales, es decir, el nórdico antiguo y las lenguas nórdicas modernas: el danés, el feroés, el islandés, el noruego y el sueco.

El punto de partida es un corpus general compuesto por léxico que hemos extraído de los diccionarios generales y específicos de la lengua española y de los bancos de datos, ${ }^{8}$ así como de diversos textos y traducciones de distintas épocas. El corpus manejado se compone de alrededor de doscientas voces; son bases léxicas, sustantivos en su mayoría, que llegaron al español, generalmente en letra impresa, por mediación de terceras lenguas a partir del siglo XIII.

El análisis de los vocablos del corpus y su agrupación en virtud de las relaciones semánticas que mantienen han dado a conocer varias áreas temáticas, entre las que figura el ámbito de la navegación y de la marina, como el de número más elevado, seguido de los que pertenecen a los terrenos de la geología y la geografía, la fauna y la ciencia, la mitología y el deporte. A otros campos corresponde un número reducido de palabras. En lo que se refiere a las fuentes documentales que ofrecen los primeros testimonios de vocablos de origen nórdico en español, podemos decir que son traducciones de obras y tratados de diversa índole, textos y relatos de viajes, libros histórico-geográficos, obras literarias, así como diccionarios y glosarios.

Este trabajo pretende dar cuenta de vocablos científicos creados a partir de nombres propios, nombres de personajes mitológicos y topónimos nórdicos, así como préstamos léxicos, que han sido incorporados al español desde finales del siglo XVIII hasta el siglo XX. Conviene indicar que se trata de un primer acercamiento a la recepción de estos términos científicos en el español.

8 Los bancos de datos de la Real Academia Española: $C O R D E$ = Banco de datos (CORDE) [en línea]: Corpus diacrónico del español: http://www.rae.es; CREA = Banco de datos (CREA) [en línea]. Corpus de referencia del español actual. http://www.rae.es; NTLLE = Nuevo tesoro lexicográfico de la lengua española. [en línea]: http://www.rae.es; NDHE = Instituto de investigación Rafael Lapesa de la Real Academia Española (2013-): Nuevo diccionario bistórico de la lengua española (NDHE) [en línea]: http://www.eb.frl.es. $C D H=$ Real Academia Española, Corpus del diccionario histórico. http://www. rae.es. $F G=$ Real Academia Española, Fichero General. http://www.rae.es. DLE = Real Academia Española, Diccionario de la lengua española, http://www.rae.es. DICTER = Mancho Duque, María Jesús (dir.), Diccionario de la ciencia y de la técnica en el Renacimiento, http://dicter.usal.es/. HD = Biblioteca Nacional de España, Hemeroteca digital http://www.bne.es/es/Catalogos/ Hemeroteca Digital/. CORPES XXI = Real Academia Española, Corpus del Español del Siglo XXI, https://www. rae.es. 


\section{Términos científicos de origen nórdico}

Los quince términos seleccionados para el presente estudio pertenecen al ámbito de la ciencia, y a los subcampos de la química y de la física. A la terminología de la física corresponden cuatro voces: ángstrom, celsio o celsius, oersted y sievert. Al terreno de la química pertenecen las siguientes once voces: escandio, hafnio, holmio, erbio, iterbio, itrio, terbio, nobelio, torio, tungsteno, vanadio.

Los términos que proceden de unidades léxicas suecas son diez: ángstrom, celsio o celsius, holmio, nobelio, iterbio, itrio, erbio y terbio, sievert y tungsteno; del danés son dos: hafnio y oersted, y del nórdico antiguo son tres: escandio, torio y vanadio.

Las denominaciones que tienen como fuente la mitología nórdica son torio y vanadio. La creación de términos por metonimia y más concretamente, las palabras que se forman a partir de topónimos nórdicos son: escandio, hafnio, holmio, erbio, iterbio, itrio y terbio. Se trata por lo general de nombres que refieren el lugar del descubrimiento del elemento que denominan.? Por otro lado, los términos que tienen como fuente los nombres propios, los así llamados deonomásticos, son: ángstrom, celsio, nobelio, oersted y sievert. El término tungsteno es un préstamo léxico, es decir, una palabra nominal común, que viene de la lengua sueca.

Los tecnicismos químicos se componen, por un lado, del elemento léxico prestado y, por el otro, de la terminación -io, empleada en la formación de términos químicos. La desinencia - io proviene del latín -ium, forma esta última que se ha conservado en muchas otras lenguas en las que se encuentran las voces estudiadas. Cabe mencionar, por ejemplo, hafnium, holmium y nobelium en inglés, francés y alemán.

Por otra parte, los términos físicos que nos ocupan se crean a partir de los apellidos de ilustres científicos nórdicos que promovieron el avance del conocimiento físico en su época. Estas denominaciones suelen aparecer sin modificaciones tal como revelan los casos de sievert, oersted, celsius. Ángstrom es una forma que entra a través del francés, por ser el apellido del físico sueco Ångström; ${ }^{10}$ nobel lleva el sufijo -um, nobelium, y llega a ser nobelio en español.

9 Martín Camacho, José Carlos, "Los procesos neológicos del léxico científico. Esbozo de clasificación”, Anuario de Estudios Filológicos, XXVII, pp. 157-174.

10 El apellido, Ångström, se pronuncia /óngstroem/en sueco. 
Respecto al proceso de incorporación de los elementos léxicos prestados, observamos que se registran en la lengua española a partir del siglo XVIII. Estos términos pasan al español a raíz de la revolución científica que tuvo lugar en el último tercio del siglo XVIII y en la primera mitad del siglo XIX, época que marcó el paso a la ciencia moderna y durante la cual se sentaron las bases de la terminología de la ciencia y de la técnica. ${ }^{11}$ La nueva nomenclatura química y física llega, en la mayoría de los casos, a través de las traducciones de textos científicos. $^{12}$

Tal y como se ha mencionado con anterioridad, en la lengua española las fuentes primarias utilizadas para documentar el léxico específico de la ciencia son las diversas traducciones de libros y tratados científicos. Se trata sobre todo de textos franceses y, en algunos casos, ingleses o alemanes. Una parte de las palabras estudiadas tiene su primera documentación en traducciones de libros y nomenclaturas del siglo XVIII y del siglo XIX. Otras se registran por primera vez en revistas y periódicos a finales del siglo XIX y a principios del siglo $\mathrm{XX}$. A modo de ejemplo pueden mencionarse las obras, en las que se encuentran por primera vez algunos de los tecnicismos nórdicos aquí objeto de estudio, de Louis-Bernard Guyton Morveau, Antoine-Laurent Lavoisier, Claude-Louis Berthollet y Antoine-François Fourcroy, Método de la nueva nomenclatura química, un libro traducido del francés por Pedro Gutiérrez Bueno y publicado en 1788; Nueva nomenclatura química según la clasificacion adoptada por Mr. Thenard... de Joseph Bienaimé Caventou, texto traducido del francés por Higinio Antonio Lorente en 1818; de Apollinaire Bouchardat, Elementos de química: aplicada a las artes, a la industria y a la medicina traducido por D. P. Bofi$1 l$ y D. I. Martí en 1843; el Tratado de química por Jöns Jacob Berzelius

11 Apollinaire Bouchardat, en Elementos de química: aplicada a las artes, a la industria y a la medicina, Barcelona: Imprenta A. Gaspar frente la Lonja, de 1843, escribe que "La nomenclatura química actualmente adoptada es una obra grandiosa que solo data desde fines del siglo XVIII", p. 14. El libro fue traducido del francés por Bofill y Martí.

12 Véase, a este respecto, Gutiérrez Cuadrado, Juan, "Lengua y ciencia en el siglo XIX español: el ejemplo de la química” en Bargallo, Maria, Esther Forgas, Cecilio Garriga, Ana Rubio y Johannes Schnitzer (eds.), Las lenguas de especialidad y su didáctica, Tarragona: Universitat Rovira i Virgili, 2001, pp. 181-196. Gutiérrez Cuadrado, Juan, "Notas sobre la traducción científica y técnica en el siglo XVIII" en Alsina, Victòria, Jenny Brumme, Cecilio Garriga y Carsten Sinner (eds.), Traducción y estandarización: la incidencia de la traducción en la historia de los lenguajes especializados, Madrid/Frankfurt am Main: Iberoamericana-Vervuert, 2004, p. 35. Garriga, Cecilio, "La química y la lengua española en el siglo XIX", Asclepio, LV/2, 2003, pp. 93-117. 
traducido del francés al castellano por Rafael Sáez Palacios y Carlos Ferrari Scardinos y publicado en 1845;13 Arte de ensayar con el soplete cualitativa y cuantitativamente, los minerales, aleaciones y productos metalúrgicos, de Carl Friedrich Plattner, traducido del inglés por Ignacio Fernández de Henestrosa y publicado en 1853; el libro de Mateo Pedro Orfila Elementos de Química Médica con aplicacion á la Farmacia y á las Artes, de 1818 y 1822; la obra de Francisco Álvarez Nuevos elementos de química: aplicada a la medicina y a las artes..., de 1838; de Ferdinand Hoefer, Nomenclatura y clasificaciones químicas: seguidas de un léxico bistórico sinonímico que comprende los nombres antiguos, las fórmulas, los nombres nuevos, el nombre del autor y la fecha del descubrimiento de los principales productos de la química, publicada en Madrid en 1853; la obra de Piñerúa Álvarez Principios de química mineral de 1898 y 1901; el discurso de ingreso a la Real Academia del ingeniero Esteban Terradas, Neologismos, arcaísmos y sinónimos en plática de ingenieros, de $1946,{ }^{14}$ y muchas obras más.

\section{Escandio, hafnio, bolmio y otros términos científicos de origen nórdico en español}

En los siguientes apartados nos ocupamos de modo específico de los términos científicos de origen nórdico acuñados en la lengua española. Primero consideraremos los términos químicos - escandio, hafnio, holmio, tungsteno, erbio, iterbio, itrio, terbio, nobelio, torio y vanadio - para luego dirigir la vista hacia cuatro términos físicos, angstrom, celsio/celsius, sievert y oersted.

13 Según Muñoz Bello, el manual de Berzelius se tradujo a partir de la cuarta edición alemana de 1838, edición traducida al francés y esta al español en 1845. Muñoz Bello, M. Rosa, "La notación química: El lenguaje algebraico de Berzelius en España”, Cecilio Garriga Escribano, María Luisa Pascual y María Betulia Pedraza (eds.), Lengua de la ciencia y lenguajes de especialidad, A Coruña: Universidade da Coruña, Servizo de Publicacións, 2019, pp. 241-258.

14 Para más información véase los trabajos de Garriga Escribano, Cecilio, "La recepción de la Nueva nomenclatura química en español”, Grenzgänge 8/1997, pp. 33-48. Bertomeu Sánchez, José Ramón y Rosa Muñoz Bello, "Azoote y sulfureto. Debates y propuestas en torno a la terminología química durante la primera mitad del siglo XIX”, Revista de Investigación Lingüística, $\mathrm{n}^{\circ} 13$ (2010), pp. 270-306. Muñoz Bello, Rosa, Los manuales de química en España (1788-1845): Protagonistas, terminología, clasificaciones y orden pedagógico. Valencia: Universitat de Valencia. 2015. Tesis doctoral inédita. 


\subsection{Los términos químicos}

\subsubsection{Escandio}

El elemento químico metálico de número atómico 21 se denomina escandio. Se describe de tal manera que es de color gris con tintes rosáceos; es escaso en la corteza terrestre, donde se encuentra disperso en algunos minerales. El símbolo del elemento es $S c{ }^{15}$

Es voz creada a partir del latín Scandia, el topónimo de Escandinavia, por ser sueco su descubridor, y el latín científico -ium que llega a ser -io en español. ${ }^{16}$

El término científico tiene registro en la lengua española desde 1901, fecha en la que aparece en Principios de química mineral y orgánica de Eugenio Piñerúa Álvarez, según informa CORDE ${ }^{17}$ Conviene señalar que probablemente tiene registro anterior en el español, pues figura, por ejemplo, en la Gaceta de sanidad militar de $1880 .{ }^{18}$

Escandio se recoge en la obra lexicográfica desde 1917; así, Alemany y Bolufer, en su Diccionario de la lengua española de 1917, explica que es "metal muy raro descubierto en 1879 por Clève y Nilson en la gadolinita, la euxenita, etc. Tiene símbolo Sc, y su peso atómico es 44; forma sales incoloras de sabor astringente y en general poco soluble; su óxido es la escandina". ${ }^{19}$ Figura también en el diccionario de Rodríguez Navas de 1918 con la explicación de que es un "elemento que acompaña al erbio en la gadolinita; fue descubierto por Nilson el año 1879". ${ }^{20}$

El término lo recoge el diccionario de la Academia a partir de la edición de 1970 en la que se define como 'elemento químico que se encuentra en algunos minerales, ${ }^{21}$ definición que no cambia hasta la edición de 2001 y de nuevo se detectan cambios en la edición de 2014,

\footnotetext{
15 DLE.

16 DLE.

17 CORDE.

18 HD: La Gaceta de sanidad militar, 10/7 1880, p. 12. Véase también: Vidal Díez, Mónica, "El léxico de la química en el Diccionario de ideas afines elementos de tecnología (1899) de Eduardo Benot", Études Romanes de Brno, 36/2015/1, pp. 85-101.

19 NTLLE: Alemany y Bolufer, José, Diccionario de la lengua española, Madrid: Ramón Sopena, 1817.

20 NTLLE: Rodríguez Navas y Carrasco, M., Diccionario general y técnico hispano-americano, Madrid: Cultura Hispanoamericana, 1918.

21 NTLLE: DRAE-1970.
} 
ahora, pues, se define como "elemento químico metálico, de núm. atóm. 21, de color gris con tintes rosáceos y escaso en la corteza terrestre, donde se encuentra disperso en algunos minerales (Símb. Ec.).”22

Es un término que encontramos en los diccionarios generales de la lengua española. ${ }^{23}$

\subsubsection{Hafnio}

Según el DLE, hafnio es un elemento químico metálico, de número atómico 72, dúctil, brillante, de excelentes cualidades mecánicas, escaso en la corteza terrestre y usado en el control de los reactores nucleares. El símbolo del elemento es $H f$.

En cuanto a la información etimológica de la palabra, la Academia dice que procede del inglés hafnium y este del latín moderno Hafnia nombre de Copenhague, ciudad en donde se llevó a cabo su descubrimiento, y el ingl. -ium '-io'. Hafn o havn, el segundo componente del compuesto København, 'Copenhague', significa 'puerto'. El nombre de la capital danesa, København, significa 'el puerto de comercio'. Cabe indicar que parece tratarse de un error de los lexicógrafos académicos al indicar que tanto hafn como -ium procedan del inglés.

Hafnio tiene documentación en la lengua española desde 1923, fecha en la que se testimonia en Madrid científico, revista en la que leemos lo siguiente: "comunican los químicos dinamarqueses D. Coster y G. Hevesy, haber descubierto un nuevo cuerpo simple al que han llamado Hafnio (derviación del nombre dinamarqués de Copenhague)." ${ }^{4}$ El diccionario de la Academia incluye el término estudiado desde la edición de 1970 hasta la actual, la de 2014. ${ }^{25}$

El término científico se encuentra incluido en la mayoría de diccionarios generales de la lengua española.

22 DLE.

23 Cabe mencionar los más destacados: DRAE = Real Academia Española, Diccionario de la lengua española, Madrid: Espasa, 2014. DEA = Seco, Manuel, Olimpia Ramos y Gabino Ramos, Diccionario del español actual, Madrid: Aguilar, 1999, DUE = Moliner, María, Diccionario de uso del español, Madrid: Gredos, 2004 y el DGILE = VOX, Diccionario general ilustrado de la lengua española, Barcelona: VOX, 1995.

24 HD: Madrid Científico, $\mathrm{n}^{\circ} 1.087,1923$, p. 7. El Sol, 9 de febrero de 1923, p. 6.

25 NTLLE. DLE. 


\subsubsection{Holmio}

Holmio es un elemento químico metálico del grupo de los lantánidos, de brillo metálico y escaso en la corteza terrestre. Es de número atómico 67 y su símbolo es $\mathrm{Ho}^{26}$

Es del latín científico bolmium, y este del latín moderno Holmia 'Estocolmo', en cuyos alrededores se hallaron minerales que contenían este elemento, y el latín científico -ium '-io'. Holm, que forma parte del nombre de la capital sueca, significa 'islote. ${ }^{27}$

El testimonio más antiguo encontrado de holmio consta en La Gaceta de sanidad militar del año 1880. ${ }^{28}$ En 1917 se recoge en el Diccionario de la lengua española de Alemany y Bolufer con el valor de 'metal hallado en la erbina'; se informa además que fue descubierto por Cleve en 1879, y que su símbolo es Ho. ${ }^{29}$ Derivado de bolmio es holmina, 'óxido natural de holmio'. Una información parecida se encuentra en el diccionario de Rodríguez Navas, de 1918.

El término se encuentra en el diccionario académico desde la edición de 1970 con el valor de 'metal del grupo de las tierras raras'. Se informa además de que procede de la "última sílaba de de Stock [holm\}, Estocolmo" ${ }^{30}$ En las ediciones que siguen no hay cambio en el artículo hasta la edición de 2001 y 2014.

Para terminar, cabe decir que holmio es un tecnicismo que encontramos en los diccionarios generales de la lengua española.

\subsubsection{Itrio, terbio, erbio e iterbio}

El nombre de la localidad sueca Ytterby ha dado lugar a cuatro términos químicos de los que ahora nos ocuparemos. Ytterby, que se encuentra a unos 35 kilómetros de la capital sueca, es conocida por las minas en las que se encontraron tierras raras, o grupos de elementos

26 DLE

27 Norstedts, Spanska. Spansk-svensk/Svensk-spansk ordbok, Lombarda: Rotolito, 2003, p. 231.

28 HD: La Gaceta de sanidad militar, 1880. Vidal Díez, "El léxico de la química en el Diccionario de ideas afines elementos de tecnología (1899) de Eduardo Benot", p. 94.

29 NTLLE: Alemany y Bofuler, 1917.

30 NTLLE: DRAE-1970.

58 Milli mála 12/2020 
químicos desconocidos hasta finales del siglo XVIII. ${ }^{31}$ Algunos de los elementos han recibido su denominación por el lugar donde fueron encontrados: Ytterby, un nombre que se compone, por un lado, de by, 'pueblo, población', y, por el otro, de ytter que quiere decir 'exterior' o 'extremo', es decir, la 'población exterior'. Entre los nuevos elementos químicos allí hallados se cuentan itrio, terbio, erbio e iterbio de los que, a continuación, hablaremos en orden cronológico.

\subsubsection{Itrio}

El primer término basado en el topónimo sueco es itrio. Se trata de un elemento químico metálico, de color gris y fácilmente oxidable, que se emplea en la fabricación de componentes electrónicos. El número atómico del itrio es 39, y su símbolo es $Y$.

El término que nos ocupa se toma del latín científico yttrium, y este de la primera parte del compuesto Ytterby, e.d. Ytter, la mencionada localidad sueca donde se halló, y el sufijo latino -ium, que, como en otros casos, llega a ser '-io' en español. Se trata de un nuevo elemento descubierto por el geólogo y químico finés Johan Gadolin al investigar, en 1794, una piedra negra procedente de una pedrera de Ytterby. En 1797, el químico sueco Anders Gustaf Ekeberg confirmó el descubrimiento de Gadolin y dio al elemento el nombre de ytterjord. ${ }^{32}$

La denominación del elemento químico se halla registrada en la lengua española desde principios del siglo XIX. Aparece por ejemplo en las Lecciones elementales de química teórica y práctica, para servir... de Louis Jacques Thénard, obra publicada en Madrid en 1816. ${ }^{33}$ Consta con la forma yttrio en la Nueva nomenclatura química según la clasificacion adoptada por Mr. Thenard... de Joseph Bienaimé Caventou, de $1818 .{ }^{34}$ El término se encuentra además en muchos

31 Baran, Enrique José, "La fascinante historia del descubrimiento de las tierras raras", Anales Académicos Nacionales de Ciencias Exactas, Físicas y Naturales, 68/2016, pp. 87-88.

32 Riksarkivet, "Johan Gadolin", Svenskt biografiskt lexikon https://sok.riksarkivet.se/sbl/Presentation. aspx?id=14634 [10.04.2020].

33 Thénard, Louis Jacques, Lecciones elementales de química teórica y práctica, para servir..., Volumen 1, Madrid, 1816, p. 329.

34 Caventou, Joseph Bienaimé, Nueva nomenclatura química según la clasificacion adoptada por Mr. Thenard..., Madrid: En la Imprenta de la Calle de la Greda, 1818, pp. 2 y 209. 
otros tratados científicos de la época, como, por ejemplo, en la obra de Mateo Pedro Orfila, Elementos de Química Médica, de 1818, donde aparece bajo las formas ittria e ittrio, ${ }^{35}$ y en Nuevos elementos de química, aplicada a la medicina y a las artes... también del año 1818, texto redactado por Francisco Álvarez en el que figura con la forma $y$ ttrio. ${ }^{36}$ Resulta interesante hacer constar que el CORDE no ofrece testimonios del vocablo anteriores al año 1853 , fecha en la que se documenta en el Arte de ensayar con el soplete, cualitativa y cuantitativamente, los minerales... de Carl Friedrich Plattner. ${ }^{37}$

El vocablo estudiado tiene registro lexicográfico desde mediados del siglo XIX. Se incluye en el Diccionario General de la Lengua Castellana, elaborado por José Caballero en 1849, con el valor de 'sustancia metálica.38 Se recoge en el Diccionario Nacional o Gran Diccionario Clásico de la Lengua Española de Domínguez de 1853 en el que se explica que pertenece al ámbito científico de la mineralogía y es una 'especie de sustancia metálica'. Interesa mencionar que en el mismo diccionario encontramos el término itria, que pertenece al campo de la química, según se informa, y que es 'sustancia terrestre, que se cree esté formada de Itria y de oxígeno, ${ }^{39}$ En el Diccionario enciclopédico de la lengua castellana... publicado por Gaspar y Roig en 1855 aparecen los términos itria 'óxido de itrio', itrífero 'sustancias minerales que contienen accidentalmente alguna cantidad de itria', itrita 'silicato de itria', itrocerita 'variedad de fluoruro de itrio que contiene cerio', itrocolumbita 'tantalatro de itria', e itroilmenita, 'sustancia de color gris que contiene entre muchos elementos itria', todos derivados de itrio. En este diccionario, los términos se marcan como pertenecientes al campo de la mineralogía. ${ }^{40}$

35 Orfila, Mateo Pedro, Elementos de Química Médica, Madrid: Imprenta de don Francisco de la Parte, 1818, p. 197.

36 Álvarez, Francisco, Nuevos elementos de química, aplicada a la medicina y a las artes... Madrid: Imprenta que fue de Fuentenebro, a cargo de Alejandro Gomez, 1838, p. 341.

37 Plattner, Carl Friedrich, Arte de ensayar con el soplete, cualitativa y cuantitativamente, los minerales, aleaciones y productos metalúrgicos, Madrid: Imprenta y estereotipía de M. Rivadeneyra, 1853, p. 198. CORDE.

38 Caballero, José, Diccionario General de la Lengua Castellana, Madrid: Imprenta de V. Domínguez, 1849, p. 827, http://bdh-rd.bne.es/viewer.vm?id=0000014395\&page=1 [10.04.2020].

39 NTLLE: Domínguez, Ramón Joaquín, Diccionario Nacional o Gran Diccionario Clásico de la Lengua Española (1846-47), Madrid/París: Establecimiento de Mellado, 1853.

40 NTLLE: Gaspar y Roig, Diccionario enciclopédico de la lengua castellana con todas las vozes, frases, refranes y locuciones usadas en España y las Américas Españolas, Madrid: Imprenta y librería de Gaspar y Roig, 1855. 
Ahora bien, itria se encuentra en el diccionario académico de 1899 con el valor de 'óxido de itrio, sustancia blanca, terrosa, insoluble en el agua y que se extrae de algunos minerales poco comunes'. En la misma edición encontramos el término itrio, 'metal que forma un polvo brillante y negruzco y cuyas demás propiedades son muy poco conocidas'. Se explica que es voz que viene de itria que, a su vez, es de "Itterby, pueblo de Suecia" ${ }^{41}$ No será hasta la edición académica de 1914 cuando aparecen cambios en la explicación etimológica de estos dos términos. Así pues, ahora itria viene de itrio y es 'óxido de itrio'; e itrio procede de Itterby, pueblo de Suecia. ${ }^{42}$ En la información no aparecen modificaciones hasta la edición de 1970, en la que itrio se dice del mismo origen que iterbio, y se organiza en el campo semántico de la química. Se ofrece además el número atómico e información sobre el símbolo del elemento. ${ }^{43}$ A partir de la edición de 1992 se suspende la entrada itria, 'óxido de itrio'.

Concluimos pues que itrio es un término químico que se encuentra en las principales obras lexicográficas monolingües de la lengua española.

\subsubsection{Terbio}

La segunda voz creada a partir del topónimo sueco es terbio. Se define como elemento químico metálico, del grupo de los lantánidos, muy reactivo y de brillo metálico, y se informa de que es muy escaso en la corteza terrestre, donde se encuentra en algunos minerales unido al itrio y al erbio. El número atómico es 65 y el símbolo del elemento es $T b^{44}$

Se trata de un término que viene del latín científico terbium, y este de terby, de Ytterby, la localidad sueca donde se encontraron las tierras raras, y, como antes se ha explicado, de -ium que da '-io' en español. ${ }^{45}$ Fue el químico sueco Carl Gustaf Mosander quien en 1842 y 1843 descubrió los elementos químicos terbio y erbio al estudiar los com-

\footnotetext{
41 NTLLE: DRAE-1899.

42 NTLLE: DRAE-1899.

43 NTLLE: DRAE-1970.

44 DLE.

45 DLE.
} 
puestos de las tierras raras. A estos elementos los nombró en homenaje al lugar de procedencia: Ytterby. ${ }^{46}$

Terbio tiene registro en el español desde mediados del siglo XIX. El vocablo figura por ejemplo en la obra de Agustín Yáñez y Girona Lecciones de historia natural: Mineralogía, publicada en Barcelona en el año $1845 .{ }^{47}$ También lo encontramos en el Diccionario de medicina, cirugía, farmacia, medicina legal, física, química, botánica, mineralogía, zoología y veterinaria elaborado por Pierre Hubert Nysten y publicado en Barcelona en $1848 .{ }^{48}$ Lo comentado arriba permite señalar que la palabra aparece mucho antes de lo que indican los datos de CORDE, pues según esta fuente, tiene sumer registro en 1946, fecha en que aparece en el tratado Neologismos, arcaísmos y sinónimos en plática de ingenieros de Esteban Terradas. ${ }^{49}$

Por lo que se refiere a la incorporación lexicográfica de este término científico, cabe decir que consta en el diccionario de Gaspar y Roig, de 1855, en el que se explica que es un 'nuevo metal descubierto en la Itria". 50

Desde 1899, el término se incorpora al diccionario académico, en el que se informa de que procede de "Therby, pueblo de Suecia" y que es 'metal muy raro, que, unido al itrio y al erbio, se ha hallado en algunos minerales de Suecia.51 En la siguiente edición académica, la de 1914, se ha corregido el nombre del pueblo sueco del que deriva el término, pues ahora se indica que es "de Itterby, pueblo de Suecia". 52 Se aclara además que es "nombre del cual se han formado también el de itrio y el de erbio". 53 En la edición de 1970 del DRAE aparece in-

46 Baran, Enrique José, "La fascinante historia del descubrimiento de las tierras raras", pp. 91-92. Hernández, Juan, "Los elementos químicos y sus nombres", Pliegos de Yuste, 4, I, 2006, p. 67. Niinistö, Lauri, "Discovery and Separation of Rare Earths" en Sáez, Regino y Paul A. Caro (eds.), Rare Earths, Madrid: Editorial Complutense, 1998, pp. 25-42. Prego Reboredo, Ricardo, Las tierras raras, Madrid: CSIC, 2019.

47 Yáñez y Girona, Agustín, Lecciones de historia natural: Mineralogía, volumen 3, Barcelona: Imprenta de Benito Espona y Blay, 1845, p. 97.

48 Nysten, Pierre-Hubert, Diccionario de medicina, cirugía, farmacia, medicina legal, física, química, botánica, mineralogía, zoología y veterinaria Volumen 1, Barcelona: Imprenta de J. Roger, 1848, p. 349.

49 CORDE.

50 NTLLE: Gaspar y Roig, 1855.

51 NTLLE: DRAE-1899.

52 NTLLE: DRAE-1914

53 NTLLE: DRAE-1914.

62 Milli mála 12/2020 
formación sobre el campo científico al que pertenece el término, el químico, así como el número atómico y el símbolo del elemento. ${ }^{54}$

Podemos añadir finalmente que este término, igual que los anteriores, se encuentra incluido en los principales diccionarios monolingües del español.

\subsubsection{Erbio}

El erbio es un elemento químico metálico del grupo de los lantánidos. Es de color gris oscuro. Es muy escaso en la corteza terrestre y suele encontrarse unido al itrio y al terbio en ciertos minerales. Se ha utilizado para fabricar filamentos de lámparas incandescentes. El número atómico es 68, y el símbolo es $E r^{55}$

Según el $D L E$, el vocablo procede del latín científico erbium, y este, a su vez, de erby, parte del topónimo Ytterby, e -ium '-io'. El elemento fue descubierto en 1843 por el químico sueco Carl Gustaf Mosander, que lo nombró erbium en honor al pueblo de Ytterby. ${ }^{56}$

El término que aquí interesa tiene documentación en el español desde la primera mitad del siglo XIX. Se halla, por ejemplo, en la obra de Agustín Yáñez y Girona, Lecciones de historia natural: Mineralogía, de $1845 .{ }^{57}$ También se encuentra en el Diccionario de medicina, cirugia, farmacia, medicina legal, física, química, botánica, mineralogía, zoología y veterinaria de Pierre Hubert Nysten, publicado en $1848 .{ }^{58}$ En la Nomenclatura y clasificaciones químicas seguidas de un léxico histórico... de Fernando Hoefer, del año 1853, topamos con una nota del traductor en la que menciona los términos tervio, ervio y didimio e indica que son elementos descubiertos por el químico sueco Karl Gustaf Mosander en $1828 .^{59}$ Debe mencionarse que figura además en muchos otros tratados y manuales de la época.

\footnotetext{
54 NTLLE: DRAE-1970.

55 DLE.

56 Juan Hernández, "Los elementos químicos y sus nombres”, p. 67. Baran, Enrique José, "La fascinante historia del descubrimiento de las tierras raras", p. 92.

57 Yáñez y Girona, Agustín, Lecciones de historia natural: Mineralogía, p. 97.

58 Nysten, Pierre-Hubert, Diccionario de medicina, cirugía, farmacia, medicina legal, física, química, botánica, mineralogía, zoología y veterinaria, p. 349.

59 Hoefer, Ferdinand, Nomenclatura y clasificaciones químicas: seguidas de un léxico bistórico, Madrid: Imprenta a cargo de Manuel A. Gil, 1853, p. 21. Cabe mencionar que Mosander descubrió estos elementos en los años 40 del siglo XIX. Véase Baran, "La fascinante historia del descubrimiento de las tierras raras", p. 85 .
} 
De acuerdo con el CORDE, erbio se documenta por primera vez en 1927 cuando aparece en la Mineralogía de Lucas Fernández Navarro. Se menciona que también consta en el texto de Esteban Terradas de 1946. El FG, por otra parte, ofrece la datación de 1901 como la fecha del primer registro de erbio, terbio e iterbio, términos que constan, según esa misma fuente, en Principios de química mineral y orgánica de Eugenio Piñerúa. ${ }^{60}$

En cuanto al recorrido lexicográfico del vocablo, conviene apuntar que se recoge en el Diccionario enciclopédico de la lengua castellana de Zerolo, de 1895, con el valor de 'metal raro afín del itrio'. ${ }^{61}$ El diccionario académico recoge el término desde finales del siglo XIX. En la edición de 1899 se explica que es 'metal muy raro que unido al itrio y terbio se ha encontrado en algunos minerales de Suecia'. Interesa mencionar que la Academia, en dicha edición de 1899, le da un origen alemán a la palabra, y así explica que es "del al. erz, mineral". ${ }^{62}$ En la edición de 1914 se ha corregido la información, pues ahora se indica que la palabra es del mismo origen que el término terbio, es decir, "De Ytterby, pueblo de Suecia, nombre del cual se han formado también el de itrio y el erbio". ${ }^{63}$ La explicación etimológica de la palabra es parecida en las sucesivas ediciones del diccionario académico hasta la edición de $2014 .^{64}$

Por tanto, erbio es un tecnicismo químico que se incluye en los principales diccionarios generales de la lengua española.

\subsubsection{Iterbio}

El cuarto término formado a partir del topónimo sueco es iterbio, un elemento químico metálico del grupo de los lantánidos. Se informa de que es muy escaso en la corteza terrestre, donde se encuentra en ciertos minerales acompañando al itrio. Algunos de sus derivados se usan en electrónica, en la industria del vidrio y como catalizadores. El número atómico es 70 , y su símbolo es $Y b^{65}$

\footnotetext{
$60 \quad F G$.

61 NTLLE: Zerolo, Elías, Diccionario enciclopédico de la lengua castellana, París: Garnier hermanos, 1895.

62 NTLLE: DRAE-1899.

63 NTLLE: DRAE-1914.

64 NTLLE. DLE.

65 DLE.
} 
Se trata de una voz tomada del latín científico ytterbium, y este de Ytterby, la localidad sueca donde se halló la erbia, tierra rara de la que viene el iterbio, y del sufijo latino -ium, o sea '-io'. En 1878, el químico suizo Jean Charles Galissard de Marignac descubrió que el erbio contenía otro elemento, al que dio el nombre yterbia. ${ }^{66}$

Esta denominación química tiene documentación en la lengua española desde finales del siglo XIX. Se halla, por ejemplo, en $L a$ gaceta de sanidad militar, periódico científico y oficial de Sanidad Militar, de $1880 .{ }^{67}$ En La Ciencia cristiana, revista quincenal de 1885, leemos que "Más tarde, por este medio del análisis espectral, se aumentó el número de los simples con otros cinco metales: el iterbio, escandio, holmio, thulio y samario" ${ }^{68}$ El CORDE aporta testimonios de la voz que datan de 1946, cuando se registra en el tratado de Esteban Terradas, y de 1973, fecha del discurso de recepción en la Real Academia Nacional de Farmacia del mineralogista y edafólogo Vicente Aleixandre Ferrandis. ${ }^{69}$ Se trata de testimonios posteriores a los arriba mencionados.

El término se recoge en los diccionarios más importantes de la lengua española. Ha sido incluido en el diccionario de Alemany y Bolufer, Diccionario de la lengua española, de 1917, con el significado de 'metal poco conocido y que parece ser análogo al itrio'. En el artículo se explica que el elemento iterbio fue aislado de las tierras itríferas por Marignac en 1878, y que el nombre procede del topónimo sueco Itterby ${ }^{70}$ Información análoga aparece en el diccionario de Rodríguez Navas, Diccionario general y técnico hispano-americano, de $1918 .^{71}$

A partir de la edición de 1970, se incluye en el diccionario académico con el valor de 'metal del grupo de las tierras raras, cuyas sales son incoloras'. Y así es la definición en las obras lexicográficas de la Academia hasta hoy día. ${ }^{72}$

\footnotetext{
66 Baran, Enrique José, "La fascinante historia del descubrimiento de las tierras raras", p. 93.

67 HD: La gaceta de sanidad militar, 10/7, 1880, p. 12.

68 HD: La Ciencia cristiana, 1885, p. 21.

69 CORDE.

70 NTLLE: Alemany y Bolufer, 1917. Vésae también Baran, Enrique José, "La fascinante historia del descubrimiento de las tierras raras", p. 93.

71 NTLLE: Rodríguez Navas y Carrasco, 1918.

72 NTLLE: DRAE. DLE.
} 
Se trata de un término que se encuentra en la mayoría de los diccionarios monolingües de la lengua española.

\subsubsection{Nobelio}

Otro elemento químico metálico, radiactivo, de número atómico 102, es el nobelio. Es del grupo de los actínidos, obtenido artificialmente por bombardeo de curio con núcleos de carbono, nitrógeno o boro, y cuya vida media es de tres minutos. El símbolo de este elemento es No. ${ }^{73}$

Su forma en latín científico es nobelium, que se deriva del nombre del inventor sueco Alfred Nobel (1833-1896), y el sufijo latino -ium, '-io' en español.

El término se documenta por primera vez, de acuerdo con la información dada por el fichero de la Real Academia Española, en 1960 cuando aparece en la obra de Félix Restrepo (1887-1965), Entre el tiempo y la eternidad. ${ }^{74}$

Con el mencionado valor el término se recoge en el diccionario académico de 1970 en el que se define como 'elemento radioactivo artificial que se obtuvo bombardeando el curio con iones de carbono'. Se menciona que viene "del instituto Nobel, donde fue descubierto". 75

Este tecnicismo se halla en todos los diccionarios generales de la lengua española consultados.

\subsubsection{Torio}

El torio es la denominación para un elemento químico metálico, radiactivo, del grupo de los actínidos. Es de color plomizo, dúctil, maleable, muy combustible y escaso en la corteza terrestre. Se utiliza en la industria nuclear y, aleado, para proporcionar dureza a algunos metales. Su número atómico es 90 y el símbolo del elemento es $T h^{76}$

El término procede del latín científico thorium, y este de Thor 'Pór', nombre del dios del trueno de la mitología escandinava, y el sufijo -

\footnotetext{
73 DLE.

74 FG.

75 NTLLE: DRAE-1970.

76 DLE.
}

66 Milli mála 12/2020 
ium que da ‘-io' en español. ${ }^{77}$ En un artículo publicado en 1830 en los anales de la Academia de Ciencas Naturales sueca, el conocido químico Berzelius escribe que "Jag har kallat mineralet thorit, och den nya metalliska kroppen thorium", 78 es decir que dio el nombre thorit al mineral recién descubierto y thorium al elemento metálico. En 1817, Berelius había encontrado tierra que denominó torjord o torina. ${ }^{79}$

"La torina es una tierra nueva que acaba de descubrir Berzelius en el distrito de Finbo, inmediato a Fahlun" escribe Mateo Pedro Orfila en su tratado de elementos químicos de $1818 .{ }^{80}$ En los años treinta del mismo siglo XIX, Francisco Álvarez menciona la torina, el torio y el torinio en Nuevos elementos de química aplicadas a la farmacia y a las artes... texto fechado en 1838. En el apartado titulado "Del torio o torinio" describe las características del elemento recién descubierto por "Bercélius en 1828". Dice que este cuerpo simple "existe en pequeña cantidad en un mineral llamado thorita, nuevo mineral de composición muy complicada, que se encuentra en muy pequeña cantidad en Brévig, en Noruega." 81 El término se encuentra en diversos tratados científicos, manuales de química y textos de ciencia traducidos y publicados a lo largo del siglo XIX.

El testimonio más antiguo que ofrece el CORDE data del año 1910, fecha en que aparece en la obra Elementos de Física general de Rodrigo Sanjurjo. ${ }^{82}$

En cuanto al recorrido lexicográfico del término que nos ocupa, cabe señalar que aparece en la obra de José Caballero, Diccionario General de la Lengua Castellana, de 1849. En el artículo de la entrada tórico se lee que: "Concerniente al torio; se dice de un ácido procedente del torio". ${ }^{3}$ La voz también se recoge en el diccionario de Domínguez de 1853 que informa de que es "metal nuevo y aún poco conocido". ${ }^{84}$ El término figura en otros diccionarios generales de la lengua

\footnotetext{
77 DLE.

$78 S A O B=$ Svenska Akademien, Svenska Akademiens Ordbok, www.saob.es [10.4.2020].

79 Nordenskjöld, I., "Ur torjordens historia", Svensk kemisk tidskrift 17/1905, p. 37, http://runeberg. org/svkemtid/1905/0041.html [10.4.2020].

80 Orfila, Mateo Pedro, Elementos de Química Médica con aplicación a la farmacia y a las artes..., 1818, p. 545.

81 Álvarez, Francisco, Nuevos elementos de química aplicadas a la farmacia y a las artes..., 1838, p. 202.

82 CORDE.

83 Caballero, José, Diccionario General de la Lengua Castellana, p. 1187.

84 NTLLE: Domínguez, Ramón Joaquín, 1853.
} 
desde el siglo XIX, y se incluye en el diccionario de la academia desde la edición de 1899 con la explicación de que es "metal pulverulento, de color plomizo, más pesado que el hierro, y que solo se ha encontrado en algunos minerales de Noruega". En la entrada se ofrece además una explicación de la procedencia del término, pues viene "de Tor, dios de la mitología escandinava". ${ }^{85}$ No hay cambios en la definición del término hasta la edición de 1970, en la que se añade el número atómico y el símbolo del elemento. En la edición de 2001 aparece una definición más detallada del elemento en cuestión: "elemento químico radiactivo de núm. atóm. 90. Metal del grupo de los actínidos escaso en la corteza terrestre, se encuentra en minerales de tierras raras. De color plomizo, dúctil y maleable, arde muy fácilmente en el aire. Se usa en la industria nuclear y, aleado, para proporcionar dureza a ciertos metales (Símb. Th, del lat. cient. thorǐum)."

Cabe indicar que el término se encuentra en la mayoría de las obras lexicográficas generales de la lengua española.

\subsubsection{Tungsteno}

El tungsteno es un elemento químico metálico escaso en la corteza terrestre. Es de color gris acerado, muy duro y denso, y con el punto de fusión más elevado de todos los elementos. Se utiliza en los filamentos de las lámparas incandescentes, en resistencias eléctricas y, aleado con el acero, en la fabricación de herramientas. Su número atómico es 74 y su símbolo es $W$ (es decir, del latín científico wolframium 'wolframio', otro de sus nombres). ${ }^{87}$

Tungsteno se toma de la forma latina científica tungstenum, y esta del sueco tungsten, palabra compuesta de tung 'pesado' y sten 'piedra', es decir, 'piedra pesada'.8 ${ }^{8}$ Fue el mineralogista sueco Alex Fredrik Cronstadt quien sugirió este nombre para el elemento, denominación que aparece en sus escritos Ensayos de mineralogía de $1758 .{ }^{89}$

\footnotetext{
85 NTLLE: DRAE-1899.

86 DRAE, 2001.

87 DLE.

88 DLE.

89 Cronstedt, Axel Fredric, Försök til mineralogie, eller mineral-rikets upställning, Stockholm, 1758, p. 183; SAOB, https://www.saob.se/artikel/?seek=tungsten\&pz=1\#U_T3009_162775. Hernández, Juan, "Los elementos químicos y sus nombres", p. 61.
} 
Este tecnicismo químico tiene documentación en la lengua española desde la segunda mitad del siglo XVIII. Bajo la forma tungsten aparece registrado en el Memorial literario instructivo y curioso de la Corte de Madrid publicado en $1785 . .^{90}$ Se halla, además, en el Método de la nueva nomenclatura química de Morveau, Lois-Bernard Guyton, Antoine-Laurent Lavoisier, Claude-Louis Berthollet y Antoine-François Fourcroy, ${ }^{91}$ texto traducido del francés por Pedro Gutiérrez Bueno y publicado en Madrid en $1788 .{ }^{92}$ En dicho texto el vocablo que nos ocupa aparece bajo la forma tustena y tunstena. ${ }^{93}$ En 1791 encontramos la forma tungstena en los Anales del Real Laboratorio de Química de Segovia de Luis Proust. ${ }^{94}$ Antoine Laurent de Lavoisier, en su Tratado elemental de Química: presentado baxo nuevo orden y conforme a los descubrimientos modernos de 1798, usa la forma tunsteno. ${ }^{95}$ La voz aparece con la grafía túngsteno en la obra Joseph Bienaimé Caventou, Nueva nomenclatura química según la clasificacion adoptada por Mr. Thenard ... de 1818. ${ }^{96}$ Es interesante observar que el CORDE propone el año 1853 como la fecha del primer registro del vocablo tungsteno en español, y como la fuente de este primer testimonio el Arte de ensayar con el soplete, cualitativa y cuantitativamente, los minerales... de Carl Friedrich Plattner. ${ }^{97}$ El DCECH sugiere por otra parte el año 1912 como la fecha de primera documentación del término y el año 1925 para la primera aparición en el diccionario académico. ${ }^{98}$

90 HD: Memorial literario instructivo y curioso de la Corte de Madrid, 10/1785, p. 14.

91 Méthode de Nomenclature Chimique, Paris: Cuchet, 1787.

92 Morveau, Louis-Bernard Guyton, Antoine-Laurent Lavoisier, Claude-Louis Berthollet y AntoineFrançois Fourcroy, Método de la nueva nomenclatura química, Madrid, 1788, http://bdh-rd.bne.es/ viewer.vm? id =0000042067\&page=1. Garriga Escribano, Cecilio, "Apuntes sobre la incorporación del léxico de la química al español: la influencia de Lavoisier”, en García Bascuñana, Juan, Birgitte Lépinette, Carmen Roig (eds.), Documents pour l'bistoire du français langue etrangere ou seconde, SIHFLES, 1996. http://dfe.uab.cat/neolcyt/images/stories/estudios/ quimica/gar1996b.pdf.

93 Morveau, Louis-Bernard Guyton, Antoine-Laurent Lavoisier, Claude-Louis Berthollet y AntoineFrançois Fourcroy, Método de la nueva nomenclatura química, pp. 39 y 90. La forma tustena es probablemente una errata.

94 CORDE.

95 Lavoisier, Antoine-Laurent de, Tratado elemental de Química: presentado baxo nuevo orden, Madrid: En la imprenta real, 1798, p. 275.

96 Caventou, Joseph Bienaime, Nueva nomenclatura química según la clasificacion adoptada por Mr. Thenard..., p. 160.

97 Plattner, Carl Friedrich, Arte de ensayar con el soplete, cualitativa y cuantitativamente los minerales, aleaciones y productos metalúrgicos, p. 198. CORDE.

98 DCECH = Corominas, Joan y José Antonio Pascual, Diccionario crítico etimológico castellano e hispánico, Madrid: Gredos, 1997, p. 695. 
Son testimonios posteriores a los encontrados en varias fuentes consultadas.

En cuanto a la incorporación lexicográfica de tungsteno, cabe señalar que se recoge en el Diccionario Nacional o Gran Diccionario Clásico de la Lengua Española, de Ramón Joaquín Domínguez, de 1853. En este diccionario encontramos además los derivados túngstico para 'el ácido que resulta de la combinación del oxígeno con el tungsteno', y túngstidos, que es 'familia de minerales que comprende al tungsteno y sus compuestos. ${ }^{9}$

El vocablo se introduce en el diccionario académico en la edición de 1899. La explicación etimológica aclara que es del sueco tungsten 'piedra pesada', una palabra compuesta por un lado de tung 'pesado' y por el otro de sten 'piedra', y se define como 'metal pulverulento, de color plomizo, casi tan pesado como el oro y muy difícil de fundir.' ${ }^{100}$ En la edición de 1914 aparece un cambio en la definición del vocablo, pues ahora es 'cuerpo simple, metálico, de color gris de acero, muy duro, muy denso y difícilmente fusible'. ${ }^{101}$ En la edición siguiente, de 1925, no se ofrece una definición del vocablo sino que se remite a la entrada volframio, ${ }^{102}$ el sinónimo de tungsteno. Así es hasta la edición de 1992, cuando se vuelve a incluir la definición anterior, es decir, la de la edición de 1914. Además se clasifica el término en el campo químico y ofrece datos como el número atómico 74 y el símbolo, $W{ }^{103}$

Tungsteno es un nordismo, en este caso una palabra compuesta sueca, que figura en los principales repertorios lexicográficos de la lengua española.

\subsubsection{Vanadio}

De acuerdo con la información brindada por el $D L E$, el vocablo vanadio consta en el español con el valor de 'elemento químico metálico'. Es de color gris claro, dúctil y resistente a la corrosión, escaso en la corteza terrestre. Es usado como catalizador y, aleado, para mejorar las

\footnotetext{
99 NTLLE: Domínguez, 1853.

100 NTLLE: DRAE-1899.

101 NTLLE: DRAE-1914.

102 NTLLE: DRAE-1925.

103 NTLLE: DRAE-1992.
} 
propiedades mecánicas del hierro, el acero y el titanio. El símbolo del elemento es $V$.

El término se toma del latín científico vanadium, y este, a su vez, del nórdico antiguo Vanadís. Se trata de uno de los nombres de Freyja, la diosa de la fertilidad de la mitología nórdica. Dís quiere decir 'diosa' y los vanir eran una estirpe de dioses de ese mundo mitológico. Snorri Sturluson, en su Edda, escribe: "Vanadís, it grátfagra goð, ástarguð “104 'Vanadís, la bella llorona, diosa del amor'. Fue el químico sueco Nils Gabriel Sefström, estudiante y discípulo del famoso químico sueco Berzelius quien, en 1831, redescubrió el elemento químico y le dio este nombre. ${ }^{105}$

Vanadio tiene documentación en la lengua española desde mediados del siglo XIX. Se recoge, por ejemplo, en Nuevos elementos de química: aplicada a la medicina y a las artes... libro redactado por el profesor de medicina y cirugía Francisco Álvarez en $1838 .{ }^{106}$ También se halla en el Tratado elemental de mineralogia: destinado a la enseñanza de esta ciencia de Francisco de Luxán, de 1845, ${ }^{107}$ y figura además en Arte de ensayar con el soplete,..., los minerales, aleaciones y productos metalúrgicos de Carl Friedrich Plattner, de $1853 .{ }^{108}$ El CORDE da esta última obra citada como la fuente de primera documentación del vocablo en la lengua española. Corominas y Pascual proponen 1884 como la fecha del primer registro de vanadio, fecha en que se atestigua en el diccionario de la Academia. ${ }^{109}$

En cuanto al refrendo lexicográfico de este término estudiado, cabe decir que se incluye en el diccionario de Domínguez publicado en 1853. Ahí se explica que es metal recién descubierto en una mina de hierro de Suecia. Derivados de vanadio son vanadito cuya definición es "género de sales que resultan de la combinación del óxido vanádico con ciertas bases"; vanadato "género de sales que resultan por la combinación del ácido vanádico con las demás bases selificables”, y tam-

104 Sturluson, Snorri, "Skáldskaparmál“, Edda Snorra Sturlusonar, Jónsson, Guðni (ed.), Reykjavík: Íslendingaútgáfan, 1954, p. 135.

105 Hernández, Juan, "Los elementos químicos y sus nombres”, p. 61.

106 Álvarez, Francisco, Nuevos elementos de química: aplicada a la medicina y a las artes..., p. 50.

107 Luxan, Francisco de, Tratado elemental de mineralogía: destinado a la enseñanza de este ciencia, Sevilla: imprenta de don José Herrera Dávila y Compañía, 1845, p. 44.

108 CORDE: Plattner, Carl Friedrich, Arte de ensayar con el soplete,..., los minerales, aleaciones y productos metalúrgicos.

109 DCECH, p. 738. 
bién figura ahí el adjetivo vanadosola para elementos que contienen vanadio. ${ }^{110}$ Tanto vanadito como vanádico aparecen en tratados químicos en fechas anteriores: constan, por ejemplo, en la obra de Apollinaire Bouchardat, Elementos de química: aplicada a las artes, a la industria y a la medicina, de $1843 .^{111}$

El término se recoge en el diccionario académico a partir de la edición de 1869 hasta la edición actual. En 1869 se explica vanadio como 'nombre dado á un metal blanco argentino, no dúctil, etc. modernamente descubierto.' ${ }^{112}$ En la edición de 1884 se define de manera más escueta: 'metal blanco argentino, no dúctil'. ${ }^{113}$ Es a partir de la edición de 1899 cuando se ofrece por primera vez una información sobre el origen del vocablo. Se aclara, pues, que es un término creado a partir "de Vanadís, diosa de la mitología escandinava". Además, a partir de esta edición, se define el término con mayor detalle: 'Metal del color, brillo y peso de aluminio, muy frágil y que arde al color rojo. Se encuentra en ciertos minerales de hierro y no tiene aplicaciones. ${ }^{114}$ En la siguiente edición, de 1914, aparece una definición aún más detallada:

\footnotetext{
Metal parecido a la plata por el color y el brillo, pero no por el peso específico, que es menor. Calentado en atmósfera de oxígeno, arde con luz muy intensa. Forma parte de varias aleaciones de aplicación industrial, y de algunos aceros, a los que dota de gran resistencia, dureza y facilidad para el temple. ${ }^{115}$
}

En la edición de 1970 hay de nuevo modificaciones en la explicación del término, pues ahora aparece con el valor de 'elemento metálico que se presenta en ciertos minerales y que se ha obtenido en forma de polvo gris. Se usa como ingrediente para aumentar la resistencia del acero'. Se informa además del campo al que pertenece y del número

110 NTLLE: Domínguez, 1853.

111 Bouchardat, Apollinaire, Elementos de química: aplicada a las artes, a la industria y a la medicina, p. 376.

112 NTLLE: DRAE, 1869.

113 NTLLE: DRAE, 1884.

114 NTLLE: DRAE, 1899.

115 NTLLE: DRAE, 1914.

72 Milli mála 12/2020 
atómico, así como el símbolo del elemento. ${ }^{116}$ No hay cambios en la definición hasta la edición de 2014, en la que se indica por fin que viene del nórdico antiguo, Vanadís. ${ }^{117}$

El término vanadio, igual que los antes mencionados, se encuentra incluido en las principales obras lexicográficas monolingües de la lengua española.

\subsection{Los términos físicos}

\subsection{1. Ángstrom}

El término físico ángstrom significa la 'unidad de longitud equivalente a la diezmilmillonésima (10-10) parte del metro’ y su símbolo es $\AA$. Se trata de una denominación basada en el apellido del físico y astrónomo sueco Anders Jonas Ångström (1814-1874), que llegó a ser experto en la espectroscopia. ${ }^{118}$

El primer testimonio de este término encontrado en la lengua española data de 1907, año en que figura en Madrid científico: revista de ciencias, ingeniería y electricidad. ${ }^{119}$ El CORDE aporta un testimonio con la fecha de 1957 como la del primer registro del vocablo angstrom; el Fichero General da 1910 para el primer Ángstrom en español y el CDH aporta para angström un testimonio que data de 1919. ${ }^{120}$

En cuanto a la incorporación del término a las obras lexicográficas, cabe decir que lo recoge el diccionario académico a partir de la edición de 1983, donde se encuentra bajo la forma angström y en cuya entrada se remite a la forma angstromio. Esta forma se define como 'unidad de longitud equivalente a una diezmillonésima de milímetro' y se informa además que el término pertenece al ámbito de la física. El vocablo, con la forma angstromio, consta en los diccionarios de la Academia hasta 1992; sin embargo, en las ediciones posteriores, solo se incluye la forma angstrom que, desde la edición de 1984, es ángstrom. ${ }^{121}$

\footnotetext{
116 NTLLE: DRAE, 1970.

117 DLE.

118 "Rama de la física que estudia los espectros" y "estudia en qué frecuencia o longitud de onda una sustancia puede absorber o emitir energía en forma de un cuanto de luz". DLE.

119 HD: Madrid científico, 1907, n ${ }^{\circ}$ 566, p. 7.

120 CORDE. CDH. FG.

121 NTLLE: DRAE, 1984.
} 
Interesa mencionar que a lo largo del siglo XX el término ha aparecido bajo varias formas: así leemos angstrom en 1964, angstromo en 1974, anstron en 1979 y angström en 1983, ${ }^{122}$ hasta llegar a la forma actual ángstrom. ${ }^{123}$

Este término físico se halla en los diccionarios generales de la lengua española con la forma ángstrom ${ }^{124} \mathrm{o}$ angström. ${ }^{125}$

\subsubsection{Celsio}

El término grado Celsius es la unidad de temperatura de la escala Celsius cuyo símbolo es ${ }^{\circ} \mathrm{C}$. El sintagma escala Celsius refiere a la escala que asigna el valor 0 al punto de fusión del hielo y el valor 100 al punto de ebullición del agua, a la presión normal. ${ }^{126}$ La denominación viene del apellido del físico y astrónomo sueco Andrés Celsius (1701-1744) quien en 1742 definió su escala partiendo de las temperaturas de ebullición y de congelación del agua. Se trata de una escala usada para expresar la temperatura del aire, del agua, de la nevera, etc.

El término Celsius tiene registro en la lengua española desde la primera mitad del siglo XIX. Se recoge por ejemplo en la obra de Mateo Orfila y Rotger, Elementos de química aplicada a la medicina, farmacia y artes, traducida al castellano y publicada en Madrid en 1822. El texto en el que figura la voz en cuestión se presenta a continuación:

\section{[...] supuestos estos dos puntos, esto es, el del hielo al fundirse y el del agua hirviendo, se divide el intervalo en cien partes iguales que se llaman gra- dos, si se quiere hacer un termómetro centígrado ó de Celsius [......1.}

La voz que nos ocupa se documenta bajo la forma Celsio en Elementos de Física general, obra de D.R. Sanjurjo publicada en Madrid en 1910. ${ }^{128}$ El CREA, banco de datos de la Real Academia Española,

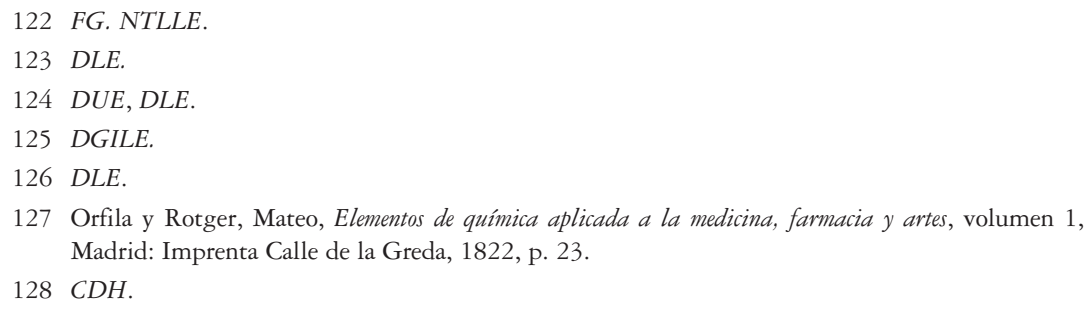


ofrece dos testimonios de este tecnicismo, el uno se fecha en 1986, el otro en $1993 .{ }^{129}$

En cuanto al refrendo lexicográfico del vocablo, cabe indicar que no consta en ningún diccionario que constituye el tesoro lexicográfico de la Real Academia Española, NTLLE. ${ }^{130}$ El diccionario de la lengua, DLE, recoge los sintagmas escala Celsius y grado Celsius. ${ }^{131}$ En el DUE, Celsius figura sin definición; así, en el artículo aparece entre paréntesis "físico y astrónomo sueco", alusión a la persona de Anders Celsus, y a continuación se remite a las entradas escala, donde se encuentra escala Celsius, y grado, donde consta grado Celsius, para una definición precisa de los sintagmas. ${ }^{132}$ El término no se encuentra en otros diccionarios generales del español.

\subsubsection{Oersted}

El elemento físico oersted es una unidad de intensidad de campo magnético en el sistema cegesimal, equivalente a 79,58 amperios por metro. El símbolo de esta unidad es $O e{ }^{133}$ El término se crea a partir del apellido del físico y químico danés Hans Christian Oersted (17771851), quien, en 1820, descubrió la acción magnética de las corrientes eléctricas.

Encontramos oersteds, la forma plural del término que nos interesa, en Neologismos, arcaísmos y sinónimos en plática de ingenieros de Esteban Terradas, tratado fechado en 1946, en el que se explica la "fuerza magnetizante o excitación magnética, en oersteds o ampervueltas por centímetros". Se trata este del primer testimonio del vocablo, según el COR$D E$ y el $C D H .{ }^{134} \mathrm{~A}$ partir de mediados del siglo $\mathrm{XX}$, topamos con este término en distintos manuales y tratados de física y de electricidad.

Por lo que se refiere a la inclusión del término en las obras lexicográficas, hay que decir que el apellido del físico danés se recoge en el Diccionario enciclopédico de la lengua castellana de Zerolo de 1895, ${ }^{135}$

\footnotetext{
129 CREA.

130 NTLLE.

131 DLE.

132 DUE, p. 1166.

133 DLE.

134 CORDE. CDH.

135 NTLLE: Zerolo, 1895.
} 
pero ahí solo se ofrece información biográfica. Una referencia parecida consta en el Diccionario general y técnico hispano-americano de Rodríguez Navas de $1918 .{ }^{136}$

No será hasta la introducción del término en el diccionario académico cuando se ofrece una definición tanto de oersted, 'el nombre del oerstedio en la nomenclatura internacional', como de oerstedio, que es, pues, la 'unidad de excitación magnética o poder imanador en el sistema magnético cegesimal'.137 En la edición del diccionario académico de 2001 se incluye el término oersted y no oerstedio, pues quedó eliminado, y lo mismo vemos en la edición más reciente. Parece que la Academia ha optado por la forma incluida en la nomenclatura internacional: oersted.

El término estudiado ha entrado a formar parte del DUE donde aparecen las dos formas mencionadas "oersted u oerstedio". El DGILE incluye las dos palabras en dos entradas distintas y con diferentes definiciones; así, oersted, que pertenece al campo de la electricidad, se define como 'unidad cegesimal electromagnética de intensidad del campo magnético', y oerstedio, en el campo físico, es 'unidad de excitación magnética o poder imanador en el sistema cegesimal.'.138

\subsubsection{Sievert}

Sievert es una unidad de equivalencia de dosis de radiación ionizante del sistema internacional, igual a 1 julio por kilogramo. Su símbolo es $S v$. El término se forma a partir del apellido del físico sueco Rolf Sievert (1896-1966). ${ }^{139}$

El término se recoge por primera vez en la edición de 1989 del diccionario manual de la Real Academia Española. Ahí consta entre corchetes y ya no en la edición siguiente, de 1992. Se define como 'unidad de dosis de radiación. ${ }^{140}$ Cabe mencionar que en el CORDE no figuran testimonios de la voz. En el CREA se halla un testimonio, pues consta en un texto cubano de 2002. ${ }^{141}$ El CDH aporta un testi-

\footnotetext{
136 NTLLE: Rodríguez Navas y Carrasco, 1918.

137 NTLLE: DRAE-1970.

138 DGILE.

139 DLE.

140 NTLLE: DRAE-1970, 1992.

141 CREA.
} 
monio que data de 1985 e informa que la voz estudiada aparece en una nota a pie de página en un texto sobre la energía solar. ${ }^{142}$ Para terminar debe mencionarse que en el CORPES XXI constan varios testimonios del término en cuestión. ${ }^{143}$

El vocablo no figura en los diccionarios generales de la lengua española consultados a excepción del $D L E$, tal como ha sido mencionado arriba.

\section{Notas finales}

En este artículo hemos realizado el primer acercamiento a la recepción en español de varios términos científicos de origen nórdico. Se trata de neologismos creados a partir de palabras, nombres propios o topónimos nórdicos, algunos de los cuales fueron creados por distinguidos químicos suecos en su época.

El presente estudio nos permite observar que los términos, cuya incorporación al español se produce desde finales del siglo XVIII hasta principios del siglo XX, se atestiguan principalmente en libros y tratados científicos confeccionados o traducidos a partir del mismo siglo XVIII. Los vocablos científicos figuran igualmente en diversos diccionarios y enciclopedias del siglo XIX. Resulta interesante poder comprobar que los primeros testimonios que ofrecen tanto el CORDE como el $C D H$ de los tecnicismos químicos y físicos estudiados son posteriores a los encontrados en las distintas fuentes consultadas, lo cual nos permite deducir que estas herramientas no reflejan fidedignamente la fecha de incorporación de estos términos. Se trata, en efecto, de una conclusión a la que ya habían llegado los estudiosos españoles en este ámbito lexicológico, cabe mencionar, por ejemplo, a uan Gutiérrez y Cecilio Garriga. ${ }^{144}$

$142 \mathrm{CDH}$.

143 CORPES XXI.

144 Véase por ejemplo Gutiérrez Cuadrado, Juan, "Lengua y ciencia en el siglo XIX español: el ejemplo de la química" en Bargalló, Maria, Esther Forgas, Cecilio Garriga, Ana Rubio y Johannes Schnitzer (eds.), Las lenguas de especialidad y su didáctica, Tarragona: Universitat Rovira i Virgili, 2001, pp. 181196. Garriga Escribano, Cecilio, "Apuntes sobre la incorporación del léxico de la química al español: la influencia de Lavoisier”, en García Bascuñana, Juan, Birgitte Lépinette, Carmen Roig (eds.), Documents pour l'bistoire du français langue etrangere ou seconde, SIHFLES, 1996. Anglada Arboix, Emilia, "Traducción y diccionario. Algunos neologismos de la química en el Nuevo diccionario francés-español (1805) de A. de Capmany", Revista de Lexicografía, IV/1997-1998, pp. 31-47. 
Por lo que se refiere a la entrada de los vocablos científicos, cabe decir que se transmitieron a la lengua española a través del francés salvo en algunos pocos casos. Habrá que tener presente que en alguna que otra ocasión, las palabras pasaron en la traducción de los textos suecos al alemán, luego al francés y de ahí al castellano. Tal es el caso del manual de química del sueco Berzelius que se tradujo a partir de la cuarta edición alemana de 1838, edición traducida al francés y esta al español en $1845 .^{145}$

Para terminar conviene señalar que de los quince términos científicos que conforman el corpus aquí objeto de estudio, once se encuentran en las principales obras lexicográficas de la lengua receptora. 


\section{ÚTDRÁTTUR}

\section{Vanadio, itrio, ángstrom... Um tækniorð af norrænum uppruna í spænsku}

Á 18. öld urðu víðtækar breytingar í heimi vísinda. Mikil og ör próun átti sér stað m.a. í náttúru- og raunvísindum. Ný pekking og nýjar uppgötvanir á sviði efna- og eðlisfræði kölluðu á ný orð yfir áđur ópekkt fyrirbæri á borð við málma, frumefni, samsett efni, ofl. Vísindamenn, par á meðal norrænir, freistuðu pess að finna nýjum efnum viðeigandi nafn og eru nokkur nýyrðanna í heimi efna- og eðlisfræði af norrænum toga. Við nýyrðasmíðina var í sumum tilvikum leitað í smiðju norrænnar goðafræði (vanadín), í öðrum hefur nýtt efni verið skírt eftir staðnum par sem pað fannst (bólmín, ytterbín) eða fengið heiti sitt af vísindamanninum sem uppgötvaði pað (angström, celsius). Mörg orðanna voru færð í latneskan búning og bárust pær orðmyndir yfir í önnur tungumál heims og teljast til albjóðaheita nú á dögum. Orð af norrænnni rót bárust úr einu tungumáli í annað, m.a. pýsku, ensku og frönsku og paðan yfir í spænsku á 18. öld og næstu aldir. Íðorðin sem hér eru í brennidepli hafa fallið að spænsku málkerfi, bæði hljóðfræðilega og beygingarlega. Í greininni er varpað ljósi á sögu fimmtán îđorða í spænsku sem eru af norrænum uppruna. Sum orðanna heyra undir svið efnafræði eins og skandín (skandíum), hafnín (bafníum), hólmín (bólmíum), nóbelín (nobelíum), tungsten, vanadíum (vanadín) erbín (erbium), terbín (terbium), ytterbín (ytterbium), yttrín (yttríum) pórín (pórium) önnur flokkast með orðum úr eðlisfræði angström, celsíus, og sívert.

Lykilorð: orðfræði - tökuorð - norræn - ^ðorð - spænska 


\section{ABSTRACT}

\section{Vanadio, itrio, ángstrom... \\ About scientific terms of Nordic origin in Spanish}

In the 18th century significant advancements occurred in science, especially in the field of natural sciences and technology. New knowledge and recent discoveries in Chemistry and Physics needed to be assigned a name; words were needed for new minerals, elements, compounds, etc. Scientists, among whom some were Nordic, created new terms whereof various have Nordic roots. Several of these neologisms derive from the vocabulary of the Nordic Mythology (vanadi$u m$ ), others are based on the name of the place where the item was discovered (itrium) or the name of the discoverer (angstrom). The words of Nordic origin soon entered other languages in their Latinized form and are today internationally used. Among other languages these have been adopted and adapted into Spanish in the period from 18th until the 20th century. In this article we shed light on the history of fifteen technical words of Nordic origin incorporated in Spanish. These words stand for chemical substances like scandium, hafnium, bolmium, itrium, terbium, erbioum iterbium, nobelium, torium, tungstenium, vanadium, and physical phenomenes like angström, celsius, oersted and sievert.

Keywords: lexicology - loanwords - Nordic - scientific terms - Spanish 


\section{REFERENCIAS BIBLIOGRÁFICAS}

Álvarez, Francisco, Nuevos elementos de química, aplicada a la medicina y a las artes... Madrid: Imprenta que fue de Fuentenebro, a cargo de Alejandro Gómez, 1838.

Anglada Arboix, Emilia, "Traducción y diccionario. Algunos neologismos de la química en el Nuevo diccionario francés-español (1805) de A. de Capmany", Revista de Lexicografía, IV/1997-1998, pp. 31-47.

Baran, Enrique José, "La fascinante historia del descubrimiento de las tierras raras", Anales Académicos Nacionales de Ciencias Exactas, Físicas y Naturales, 68/2016, pp. 87-88.

Bertomeu Sánchez, José Ramón y Rosa Muñoz Bello, “Azoote y sulfureto. Debates y propuestas en torno a la terminología química durante la primera mitad del siglo XIX", Revista de Investigación Lingüistica, 2010, pp. 270-306.

Bouchardat, Apollinaire, Elementos de química: aplicada a las artes, a la industria y a la medicina, Barcelona: Imprenta A. Gaspar frente la Lonja, 1843.

Caballero, José, Diccionario General de la Lengua Castellana, Madrid: Imprenta de la V. de D. R. J. Domínguez, 1849.

Campos Souto, Mar, Rosalía Cotelo García y José Ignacio Pérez Pascual (coord.), Historia del léxico español, A Coruña: Universidade da Coruña, 2007.

Caventou, J. B., Nueva nomenclatura química según la clasificacion adoptada por Mr. Thenard..., Madrid: En la Imprenta de la Calle de la Greda, 1818.

Clavería Nadal, Gloria, "Nuevas perspectivas en el estudio de la evolución del léxico”, en Clavería Nadal, Gloria, Margarita Freixas Alás, Marta Prat Sabater y Joan Torruella I Casañas (eds.), Historia del léxico: perspectivas de investigación, Madrid/Frankfurt am Main: Iberoamericana/Vervuert, 2012, pp. 13-90.

Cronstedt, Axel Fredric, Försök til mineralogie, eller mineral-rikets upställning, Stockholm, 1758.

Garriga Escribano, Cecilio, “Apuntes sobre la incorporación del léxico de la química al español: la influencia de Lavoisier”, en García Bascuñana, Juan, Birgitte Lépinette, Carmen Roig (eds.), Documents pour l'bistoire du français langue etrangere ou seconde, SIHFLES, 1996.

Garriga Escribano, Cecilio, "La recepción de la Nueva nomenclatura química en español”, Grenzgänge 8/1997, pp. 33-48.

Garriga, Cecilio, "La química y la lengua española en el siglo XIX", Asclepio, LV/2, 2003, pp. 93-117.

Garriga, Cecilio, María Luisa Pascual y María Betulia (eds.), Lengua de la ciencia y lenguajes de especialidad, Anexos de Revista de Lexicografía, 42, A Coruña: Universidade da Coruña, 2019.

Gutiérrez Cuadrado, Juan, "Lengua y ciencia en el siglo XIX español: el ejemplo de la química” en Bargalló, Maria, Esther Forgas, Cecilio Garriga, Ana Rubio y Johannes Schnitzer (eds.), Las lenguas de especialidad y su didáctica, Tarragona: Universitat Rovira i Virgili, 2001, pp. 181-196.

Gutiérrez Cuadrado, Juan, “Notas sobre la traducción científica y técnica en el 
siglo XVIII" en Alsina, Victòria, Jenny Brumme, Cecilio Garriga y Carsten Sinner (eds.), Traducción y estandarización: la incidencia de la traducción en la bistoria de los lenguajes especializados, Madrid/Frankfurt am Main: Iberoamericana-Vervuert, 2004.

Hernández, Juan, "Los elementos químicos y sus nombres”, Pliegos de Yuste, 4, I, 2006, http://www.pliegosdeyuste.eu/n4 pliegos/juanhernandez.pdf.

Herrera, María Teresa (dir.), Diccionario español de textos médicos antiguos (DETEMA), Madrid: Arco Libros, 1996.

Hoefer, Ferdinand, Nomenclatura y clasificaciones químicas: seguidas de un léxico histórico, Madrid: Imprenta a cargo de Manuel A. Gil, 1853

Lavoisier, Antoine Laurent de, Tratado elemental de Química: presentado baxo nuevo orden, Madrid: En la imprenta real, 1798.

Luxan, Francisco de, Tratado elemental de mineralogía: destinado a la enseñanza de este ciencia, Sevilla: imprenta de don José Herrera Dávila y Compañía, 1845.

Madrid científico, 1907, $\mathrm{n}^{\circ} 566$.

Mancho Duque, María Jesús (dir.), Diccionario de la ciencia y de la técnica en el Renacimiento, http://dicter.usal.es/ [10.4.2020].

Martín Camacho, José Carlos, "Los procesos neológicos del léxico científico. Esbozo de clasificación”, Anuario de Estudios Filológicos, XXVII, pp. 157-174.

Morveau, Lois-Bernard Guyton, Antoine-Laurent Lavoisier, Claude-Louis Berthollet y Antoine-François Fourcroy, Método de la nueva nomenclatura química, Madrid, 1788.

Muñoz Bello, M. Rosa, "La notación química: El lenguaje algebraico de Berzelius en España”, Cecilio Garriga Escribano, María Luisa Pascual y María Betulia Pedraza (eds.), Lengua de la ciencia y lenguajes de especialidad, A Coruña: Universidade da Coruña, Servizo de Publicacións, 2019, pp. 241-258.

Muñoz Bello, Rosa, Los manuales de química en España (1788-1845): Protagonistas, terminología, clasificaciones y orden pedagógico. Valencia: Universitat de Valencia. 2015. Tesis doctoral indédita.

Niinistö, Lauri, "Discovery and Separation of Rare Earths” en Regino Saez y Paul A. Caro (eds.), Rare Earths, Madrid: Editorial Complutense, 1998, pp. 25-42.

Nordenskjöld, I., "Ur torjordens historia”, Svensk kemisk tidskrift 17/1905, http:// runeberg.org/svkemtid/1905/0041.html [10.4.2020].

Nysten, Pierre-Hubert, Diccionario de medicina, cirugía, farmacia, medicina legal, física, química, botánica, mineralogía, zoología y veterinaria volumen 1, Barcelona: Imprenta de J. Roger, 1848.

Orfila, Mateo Pedro, Elementos de Química Médica, Madrid: Imprenta de don Francisco de la Parte, 1818.

Orfila y Rotger, Mateo, Elementos de química aplicada a la medicina, farmacia y artes, Volumen 1, Madrid: Imprenta Calle de la Greda, 1822.

Plattner, Carl Friedrich, Arte de ensayar con el soplete, cualitativa y cuantitativamente los minerales, aleaciones y productos metalúrgicos, Madrid: Imprenta y estereotipía de M. Rivadeneyra, 1853.

Prego Reboredo, Ricardo, Las tierras raras, Madrid: CSIC, 2019. 
Quirós García, Mariano, José Ramón Carriazo Ruiz, Emma Falque Rey y Marta Sánchez Orense (eds.), Etimología e historia en el léxico del español, Madrid/ Frankfurt am Main: Iberoamericana-Vervuert, 2016.

Riksarkivet, “Johan Gadolin”, Svenskt biografiskt lexikon, https://sok.riksarkivet. se/sbl/ Presentation.aspx?id=14634 [10.4.2020].

Rodríguez Ortiz, Francesc y Cecilio Garriga Escribano, "El Diccionario Histórico del Español Moderno de la Ciencia y de la Técnica (DHEMCYT): resultados y perspectivas" en Sinner, Carsten (coord.), Comunicación y transmisión del saber entre lenguas y culturas, Madrid: Peniope, 2013, pp. 401-410. https://dialnet. unirioja.es/servlet/libro?codigo= 559895 [10.4.2020].

Sturluson, Snorri, "Skáldskaparmál“, Edda Snorra Sturlusonar, Jónsson, Guðni (ed.), Reykjavík: Íslendingaútgáfan, 1954.

Thénard, Louis Jacques, Lecciones elementales de química teórica y práctica, para servir..., Volumen 1, Madrid, 1816.

Yáñez y Girona, Agustín, Lecciones de historia natural: Mineralogía, volumen 3, Barcelona: Imprenta de Benito Espona y Blay, 1845.

Vidal Díez, Mónica, "El léxico de la química en el Diccionario de ideas afines elementos de tecnología (1899) de Eduardo Benot", Études Romanes de Brno, 36/2015/1, pp. 85-101.

\section{Diccionarios - BANCOS DE DATOS}

$C D H=$ Real Academia Española, Corpus del diccionario histórico, http://www.rae. es [10.4.2020].

CORDE = Banco de datos (CORDE) [en línea]: Corpus diacrónico del español, http:// www.rae.es [10.4.2020].

CORPES XXI = Real Academia Española, Corpus del Español del Siglo XXI, https://www.rae.es [10.4.2020].

CREA = Banco de datos (CREA) [en línea]. Corpus de referencia del español actual, http://www.rae.es [10.4.2020].

DCECH = Corominas, Joan y José Antonio Pascual, Diccionario crítico etimológico castellano e hispánico, Madrid: Gredos, 1997.

DEA = Seco, Manuel, Olimpia Ramos y Gabino Ramos, Diccionario del español actual, Madrid: Aguilar, 1999.

DGILE = VOX, Diccionario general ilustrado de la lengua española, Barcelona: VOX, 1995.

DICTER = Mancho Duque, María Jesús (dir.), Diccionario de la ciencia y de la técnica en el Renacimiento, http://dicter.usal.es/ [10.4.2020].

$D L E=$ Real Academia Española, Diccionario de la lengua española, http://www.rae. es.

$D R A E=$ Real Academia Española, Diccionario de la lengua española, http://www. rae.es [10.4.2020].

DUE = Moliner, María, Diccionario de uso del español, Madrid: Gredos, 2004.

$F G=$ Real Academia Española, Fichero General, http://www.rae.es [10.4.2020]. 
$H D=$ Biblioteca Nacional de España, Hemeroteca digital, http://www.bne.es/es/ Catalogos/Hemeroteca Digital/ [1.06.2020].

NDHE = Instituto de investigación Rafael Lapesa de la Real Academia Española (2013-): Nuevo diccionario histórico de la lengua española (NDHE) [en línea]: http://www.eb.frl.es [10.4.2020].

Norstedts, Spanska. Spansk-svensk/Svensk-spansk ordbok, Lombarda: Rotolito, 2003.

NTLLE = Nuevo tesoro lexicográfico de la lengua española. [en línea]: http://www.rae. es [10.4.2020].

$S A O B=$ Svenska Akademien, Svenska Akademiens Ordbok, www.saob.es [10.4.2020]. 